\title{
Technology for creating electronic soil maps based on archival materials for land management engineering
}

\author{
Vitaly Garmanov ${ }^{1}$, Aleksey Osipov ${ }^{2}$, Vladimir Bogdanov ${ }^{1}$, Viktoriia Pavlova ${ }^{1}$, Ekaterina \\ Uvarova $^{1}$, Boris Zavarin ${ }^{1}$, Galina Efimova ${ }^{1}$, Vitaly Terleev ${ }^{3,4}$, and Aleksandr Nikonorov ${ }^{5, *}$ \\ ${ }^{1}$ St.Petersburg State Agrarian University, Peterburgskoe shosse, 2, St. Petersburg-Pushkin, 196601, \\ Russian Federation \\ ${ }^{2}$ A.F. Mozhaysky's Military-Space Academy, Zhdanovskaya Naberezhnaya, 13, St. Petersburg, \\ 197198, Russian Federation \\ ${ }^{3}$ Peter the Great St.Petersburg Polytechnic University, Polytechnicheskaya, 29, St. Petersburg, \\ 195251, Russian Federation \\ ${ }^{4}$ Agrophysical Research Institute, Grazhdansky pr., 14, St. Petersburg, 195220, Russian Federation \\ ${ }^{5}$ LLC «Gazprom pererabotka Blagoveshchensk», p. Gazoprovod, p. Sosenskoe, Moscow, 108814, \\ Russian Federation
}

\begin{abstract}
The article considers the structural and logical scheme of the methodology for creating electronic soil maps for land management engineering based on analog archival cartographic materials. The proposed scheme includes seven blocks: 1) building frames for 1:50,000 scale topographic map sheets in the geoinformation environment "Map 2011"; 2) scanning analog topographic maps with a scale of $1: 50000 ; 3$ ) binding a bitmap images of topographic maps to the sheet frames and cropping the frame image; 4) converting data from the GIS "Map 2011" to the GIS "MapInfo"; 5) scanning of archive analogue 1:10,000 scale soil maps and their binding to electronic 1:50000 topographic map in GIS "MapInfo"; 6) defining precision of referencing the raster 1:10,000 scale soil map to topographic 1:50,000 scale map; 7) bitmap image vectorization of a 1:10000 scale soil map in the GIS "MapInfo". The content of methodology's each block is disclosed. The developed methodology can be used for cartographic support of land management engineering and territorial planning.
\end{abstract}

\section{Introduction}

Perspective development of agricultural production is impossible without reliable coordinate-related information about the soils on which agricultural lands are located. The problem of the lack of such information is especially acute in precision irrigation agriculture. No less important is the reliable coordinate-bound information about the soil cover when substantiating design solutions in hydraulic engineering (for example, in projects of hydroameliorative systems) [1-3]. The main source of obtaining such information in modern conditions is the state fund of data obtained as a result of land management. The archives of

\footnotetext{
* Corresponding author: coolhabit@yandex.ru
} 
this fund contain cartographic materials of soil surveys. Due to the lack of modern materials of soil surveys, the topic of work on the translation of soil maps from paper to digital is very relevant. Archival cartographic materials on a paper basis, which are the sources for the creation of electronic soil maps, are not tied to any coordinate system. In the process of creating electronic soil maps, this task can be solved by means of GIS technologies, the main provisions of which are set out in this work and preliminary solutions in previously published articles $[4,6]$. The authors have developed a technology for creating electronic soil maps in the GIS environment based on archived data. Subsequently, the obtained digital soil maps are proposed to be used to form a cartogram of the suitability of lands for use in agriculture in accordance with the classification of lands for the suitability of their use in agricultural production [7].

The research is based on the following hypothesis: as a result of the development of technology for creating electronic soil maps in the GIS environment based on archival materials and the formation on their basis of a cartogram of land suitability for use in agricultural production (suitability cartogram), the quality of information support for land management design will be improved. The expected result of the application of such information support is an increase in the environmental acceptability and economic feasibility of the application of agrotechnologies in agriculture (including irrigation systems), as well as the design, design, exploitation.

Archival cartographic materials are stored in the Fund as analog (paper) maps created in a conditional coordinate system, which makes it difficult to use them in land management engineering. Therefore, the subject of this work is very relevant [8-14].

The study was based on the following hypothesis: development of a methodology for creating electronic soil maps based on archival materials in GIS environment will improve the quality of information support for land management engineering [15-20].

\section{Materials and methods}

The purpose of the study is to develop a methodology for creating electronic soil maps in the coordinate system adopted for land management engineering based on analog archival cartographic materials.

The object of research is information support for land management engineering.

The subject of the study is the conversion of analog soil maps from a conditional coordinate system into electronic maps of the coordinate system adopted for land management engineering.

Method of research. Cartographic and geoinformation research methods were used in the course of the work.

The developed technology can be successfully applied in the information support of works:

1. on the formation of natural-agricultural systems;

2. on solving optimization ecological and economic problems in the field of agricultural use of the territory;

3. on land management design and especially on-farm design;

4. on the development of territorial planning schemes;

5. substantiation of engineering solutions in the design, construction, operation and reconstruction of hydraulic structures.

\section{Results and discussion}

The developed methodology consists of seven blocks: 
1. building frames for 1:50,000 scale topographic map sheets in the geoinformation environment "Map 2011";

2. scanning analog topographic maps with a scale of 1:50000;

3. binding a bitmap images of topographic maps to the sheet frames and cropping the frame image;

4. converting data from the GIS "Map 2011" to the GIS "MapInfo";

5. scanning of archive analogue 1:10,000 scale soil maps and their binding to electronic 1:50000 topographic map in GIS "MapInfo";

6. defining precision of referencing the raster 1:10,000 scale soil map to topographic 1:50,000 scale map;

7. bitmap image vectorization of a 1:10000 scale soil map in the GIS "MapInfo".

The first block. In order to build frames of topographic map sheets for the investigated territory it is necessary to select a map classifier of the corresponding scale, In our case, it is a scale of 1:50000. After that their frames are built in the state coordinate system using GIS tools "Map 2011".

The second block. An analog topographic map is scanned using a large-format scanner. The scanner used should translate the analog image of the card into its digital image with a resolution of at least $1000 \mathrm{dpi}$ in TIFF, PCX or BMP formats. It is allowed to have a resolution of at least $300 \mathrm{dpi}$ (the best option is $508 \mathrm{dpi}$ ) to solve our problem.

The third block. Its implementation includes loading each created bitmap into GIS "Map 2011 " and its automatic binding to the corners of the trapezoid frame. Then the bitmap frame is automatically trimmed, Figure 1.

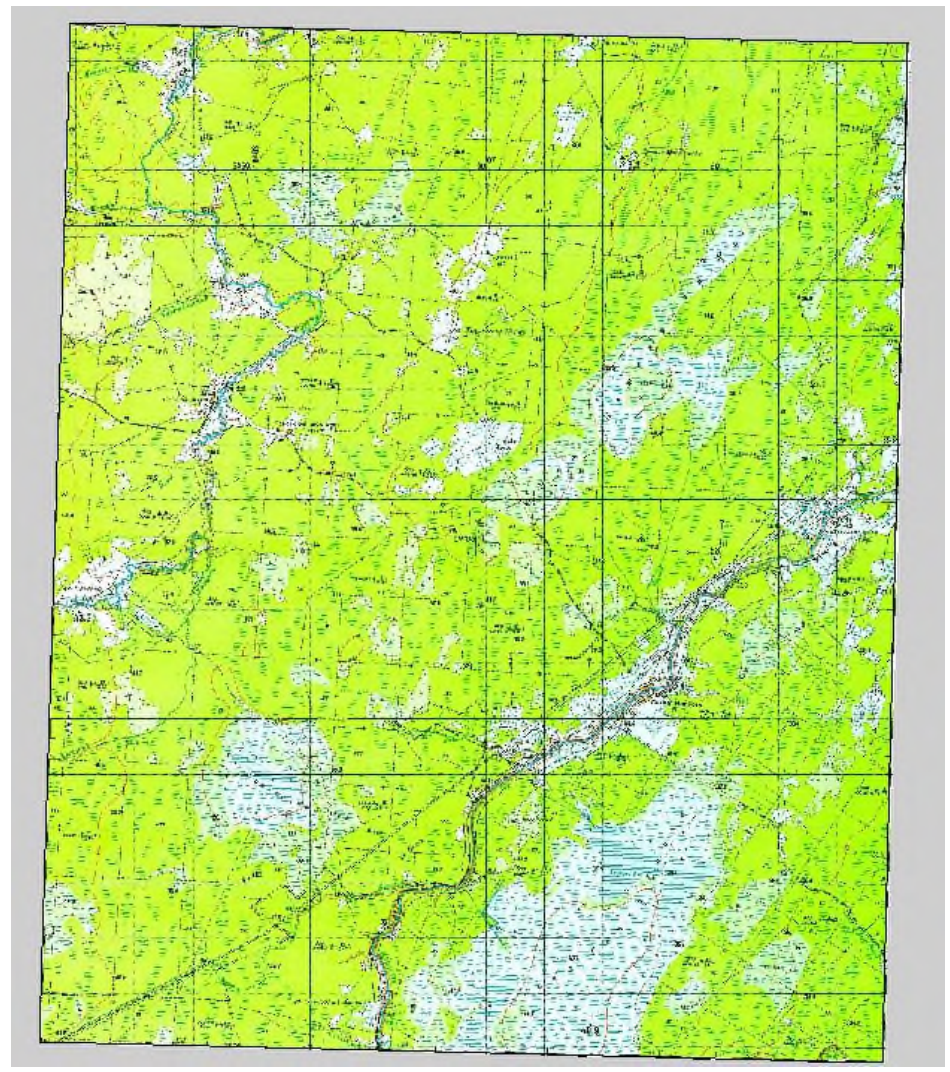

Fig. 1. A binded and trimmed 1:50000 scale map sheet. 
The fourth block. It includes the translation of trapezium frame angular coordinates from the State coordinate system to the local coordinate system. In our case, it is MCK-63. After that, the bitmap image of topographic map sheets in scale 1:50000 is converted from GIS "Map 2011" into GIS "MapInfo" and bridging to the local coordinate system MSK-63 at their corners.

The fifth block. Scanning of archive analog 1:10000 scale soil maps is carried out in accordance with the provisions specified in the second block of the methodology. Then 1: 10000 scale soil bitmaps are binded in the GIS "MapInfo" to a 1:50000 scale topographical bitmap based on the image of terrain objects. At the same time, the binding takes advantage of linear objects, Fig. 2.

The sixth block. The precision of the 1:10000 scale soil bitmap referencing to a 1:50000 scale topographic bitmap is characterized by deviations in the coordinates of the referenced bitmap objects from the coordinates of similar original bitmap objects. Coordinates of objects on initial 1:50000 scale topographic map are obtained by their measurement on production print or permanent storage diapositive, and coordinates of objects on binded bitmap are read from monitor screen. The double scale accuracy of the original topographic map is defined as the allowed discrepancy $(d c p \leq 2 t)$. The main technological operations for creating digital soil maps are shown in Fig. 3.

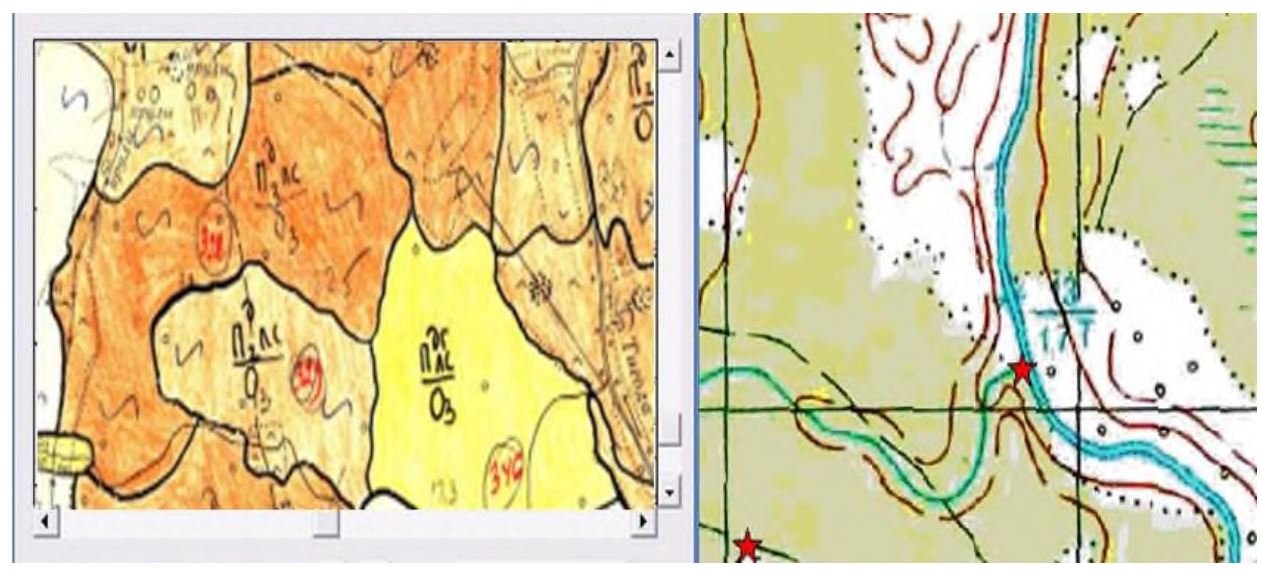

Fig. 2. Bind a 1:10000 scale soil bitmap to a 1:50000 scale topographic bitmap. 
The first stage is the construction in the GIS "Map 2011" environment of the frames of the sheets of topographic maps at a scale of 1: 50,000

Second stage - scanning analog topographic maps

The third stage - data conversion from GIS "Map 2011" to GIS

The fourth stage is the conversion of analog archive soil cartographic materials into a raster format and their binding to a topographic map at a scale of $1: 50,000$

The fifth stage is the creation of a vector layer and vectorization of the raster image of the soil map

The sixth stage - determining the accuracy of the binding of a raster soil map of a scale of 1: 10000 to a topographic map of a scale of 1 :

Seventh stage - creation of a cartogram of land suitability for agricultural use.

Fig. 3. The main technological operations for creating digital soil maps.

$$
\begin{gathered}
d=\sqrt{\left(x_{2}-x_{1}\right)^{2}+\left(y_{2}-y_{1}\right)^{2}} \\
d_{c p}=\sum d / n
\end{gathered}
$$

where $x_{1}, y_{1}$ - coordinates of object on 1:50000 scale topographic map; $x_{2}, y_{2}$ - coordinates of the object on the 1:10000 scale soil bitmap; $d$-difference in object position.

If the difference in object position exceeds the allowed values, bitmap binding is performed again.

The seventh block. Before bitmap image vectorization of a soil map, an attribution table structure is created that includes the following soil data: soil type; name of the soil; parent rock material; soil texture; soil gleying; quality score attributed to soil, soil contour area. Information for its formation is taken from the legend of the soil map and the materials of soil surveys of farms. Vectorization of soil contours is performed in GIS "MapInfo" on bitmap substrate using "Polygon" tool.

The resulting soil map in vector format (vector layerl of the digital soil map) can be used to create a cartogram of the suitability of land for agricultural use. The resulting cartogram, which is based on the classification of lands according to the suitability of lands for agriculture, uses the classification of soils and lands according to L. Blagovidov to display qualitative indicators through quantitative ones (in particular, bonitet scores). To build a cartogram in the GIS MapInfo environment, the function "Create a thematic map" is used by grouping soils according to a qualitative criterion - soil bonitet (Table 1). Accordingly, the 
quality of land determines the technology of their use, the composition of measures to preserve and improve land fertility.

Table 1. Soil and land classification scale (according to L. Blagovidov).

\begin{tabular}{|c|c|}
\hline Bonitet score & Qualitative characteristics of soils and lands \\
\hline $71-100$ & The best soils and lands \\
\hline $41-70$ & The average soils and lands \\
\hline $11-40$ & The worst soils and lands \\
\hline $1-10$ & Not used in agriculture \\
\hline
\end{tabular}

\section{Conclusion}

Advantages of the above mentioned methodology are manifested in the fact that it allows to obtain information on soils of the investigated territory in a short time with the necessary quality. Its practical application will significantly reduce labor and material costs for the creation of a base material for land management engineering and spatial planning.

The advantage of the considered technology is that it allows to obtain information about the soils of the study area in a short time with the necessary quality. Its practical application will significantly reduce labor and material costs for the creation of a planned basis for land planning and spatial planning, will create an objective basis for improving the quality of project work in various spheres of practical agriculture and hydraulic engineering construction. Of great importance is the expected positive environmental and economic effect from the implementation of the results obtained in the study.

\section{References}

1. A.I. Kim, Interexpo Geo-Siberia 1(1), 120-122 (2005)

2. A.S. Klimova, S.I. Tkachev, Collection of articles of the All-Russian Scientific and Practical Conference (FSBOU "Saratov State Agrarian University named after N.I. Babilov", 2019)

3. A.G. Osipov, V.V. Garmanov, I.B. Gengut, Land administration, inventory and monitoring of land 1, 44-49 (2016)

4. A.G. Osipov, Information and space 1, 123-130 (2016)

5. A.S. Tyrov, A.N. Kutliyarov, Management of real estate objects and territory development. Compilation of articles of the international scientific and practical conference (FSBOU "Saratov State Agrarian University named after N.I. Babilov", 2017)

6. V.V. Garmanov, A.G. Osipov, V.V. Terleev, A.R. Grik, Proceedings of the St. Petersburg State Agrarian University 2(47), 268-275 (2017)

7. Guidelines for land classification (Agropromizdat, 1986)

8. R.A. Poluektov, I.V. Oparina, V.V. Terleev, Russian Meteorology and Hydrology 11, 61-67 (2003)

9. V. Terleev, A. Nikonorov, I. Togo, Y. Volkova, V. Garmanov, D. Shishov, V. Pavlova, N. Semenova, W. Mirschel, Procedia Engineering 165, 1776-1783 (2016) 
10. I. Dunaieva, W. Mirschel, V. Popovych, V. Pashtetsky, E. Golovastova, V. Vecherkov, A. Melnichuk, V. Terleev, A. Nikonorov, R. Ginevsky, V. Lazarev, A. Topaj, Advances in Intelligent Systems and Computing 983, 236-246 (2019)

11. A. Nikonorov, V. Badenko, V. Terleev, I. Togo, Y. Volkova, O. Skvortsova, O. Nikonova, S. Pavlov, W. Mirschel, Procedia Engineering 165, 1731-1740 (2016)

12. V.V. Terleev, A.O. Nikonorov, I. Togo, Yu.V. Volkova, R.S. Ginevsky, V.A. Lazarev, E.R. Khamzin, V.V. Garmanov, W. Mirschel, L.I. Akimov, Magazine of Civil Engineering 70(2), 84-92 (2017)

13. V. Terleev, W. Mirschel, A. Nikonorov, V. Lazarev, R. Ginevsky, A. Topaj, K. Moiseev, V. Pashtetsky, I. Dunaieva, V. Popovych, A. Melnichuk, M. Arkhipov, Advances in Intelligent Systems and Computing 983, 462-471 (2019)

14. V. Terleev, W. Mirschel, A. Nikonorov, R. Ginevsky, V. Lazarev, V. Pavlova, A. Topaj, V. Pashtetsky, I. Dunaieva, V. Popovych, A. Melnichuk, K. Layshev, Advances in Intelligent Systems and Computing 983, 449-461 (2019)

15. T. Orlova, A. Melnichuk, K. Klimenko, V. Vitvitskaya, V. Popovych, I. Dunaieva, V. Terleev, A. Nikonorov, I. Togo, Y. Volkova, W. Mirschel, V. Garmanov, IOP Conference Series: Earth and Environmental Science 90(1), 012110 (2017)

16. O. Skvortsova, A. Dashkina, E. Petrovskaia, V. Terleev, A. Nikonorov, V. Badenko, Y. Volkova, S. Pavlov, MATEC Web of Conferences 53, 01014 (2016)

17. R.A. Poluektov, V.V. Terleev, Russian Meteorology and Hydrology 12, 73-77 (2005)

18. R.A. Poluektov, V.V. Terleev, Russian Meteorology and Hydrology 11, $70-75$ (2002)

19. N. Arefiev, M. Mikhalev, D. Zotov, K. Zotov, N. Vatin, O. Nikonova, O. Skvortsova, S. Pavlov, T. Chashina, T. Kuchurina, V. Terleev, V. Badenko, Y. Volkova, V. Salikov, K. Strelets, M. Petrochenko, A. Rechinsky, Procedia Engineering 117, 32-38 (2015)

20. V. Terleev, A. Nikonorov, V. Badenko, I. Guseva, Y. Volkova, O. Skvortsova, S. Pavlov, W. Mirschel, Advances in Civil Engineering 2016, 8176728 (2016) 